\title{
The quadrivalent HPV vaccine is protective against genital warts: a meta-analysis
}

\author{
Anita Lukács ${ }^{1 *}$ (D), Zsuzsanna Máté ${ }^{1}$, Nelli Farkas², Alexandra Mikó ${ }^{2}$, Judit Tenk², Péter Hegyi², Balázs Németh ${ }^{3}$, \\ László Márk Czumbel ${ }^{4}$, Sadaeng Wuttapon ${ }^{4}$, István Kiss ${ }^{3}$, Zoltán Gyöngyi ${ }^{3}$, Gábor Varga ${ }^{4}$, Zoltán Rumbus ${ }^{2}$ and \\ Andrea Szabó ${ }^{1}$
}

\begin{abstract}
Background: The quadrivalent human papillomavirus (HPV) vaccine has been assumed to give protection against genital warts (GW) as well as cervical cancer. Our main question was whether HPV vaccine has any effects on the prevention of GW reported in randomised controlled clinical trials (RCTs) and time-trend analyses.

Methods: This meta-analysis was performed according to the PRISMA guidelines using the PICO format. We searched in three electronic databases (PubMed, Embase, Cochrane Trials), and assessed heterogeneity using the Q-test and Isquared statistics, meta-regression was also performed. Odds ratios (OR) and their confidence intervals (Cl) were calculated. The sensitivity was tested by leave-one-out method. We evaluated the presence of publication bias using the funnel plot graph and the Copas selection model. The strength of evidence was assessed using the GRADE approach.

Results: Eight RCTs (per-protocol populations) and eight time-trend ecological studies were included in this meta-analysis. A significant reduction (pooled $\mathrm{OR}=0.03,95 \% \mathrm{Cl}$ : $0.01-0.09$; I-squared $=53.6 \%$ ) of $\mathrm{GW}$ in young women was recorded in RCTs, and in time-trend analyses both in young women (pooled OR=0.36, Cl 95\% $=0.26-0.51$; l-squared $=98.2 \%$ ), and in young men (pooled $\mathrm{OR}=0.69,95 \% \mathrm{Cl}=0.61-0.78$; l-squared $=92.7 \%$ ). In subgroup analysis, a significant reduction of the number of GW events was observed especially in women under 21 years (pooled $\mathrm{OR}=0.33,95 \% \mathrm{Cl}=0.17-0.63$ ). Leave-one-out analysis showed that similar results could be obtained after excluding one study, meta-regression did not show significant difference.
\end{abstract}

Conclusions: Prophylactic, quadrivalent HPV vaccination can prevent GW in healthy women and men, therefore, it should be included in routine immunization programme.

Keywords: Human papillomavirus, Vaccination, Prevention, Genital wart

\section{Background}

Human papillomaviruses (HPV) are sexually transmitted infectious agents and are increasingly common in young people. Three HPV vaccines are currently available worldwide which cover 2, 4, or 9 HPV genotypes [1]. The bivalent vaccine (Cervarix ${ }^{\oplus}$; GlaxoSmithKline)

\footnotetext{
* Correspondence: lukacs.anita@med.u-szeged.hu

'Department of Public Health, Faculty of Medicine, University of Szeged, Dóm tér 10, Szeged 6720, Hungary

Full list of author information is available at the end of the article
}

targets HPV types 16 and 18, which are associated with $70-80 \%$ of cervical cancers globally. Besides these two genotypes, the quadrivalent vaccine (Gardasil ${ }^{\circ}$; Merck \& Co) - which was licensed by the US Food and Drug Administration (FDA) in 2006 - also targets HPV types 6 and 11, associated with $85-95 \%$ of cases of genital warts (GW). Recently a nine-valent (HPV 6/11/16/18/31/33/ 45/52/58) HPV vaccine (Gardasil ${ }^{\circ}$; Merck Sharp \& Dohme Corp) has been licensed, which provides high

(c) The Author(s). 2020 Open Access This article is licensed under a Creative Commons Attribution 4.0 International License, which permits use, sharing, adaptation, distribution and reproduction in any medium or format, as long as you give appropriate credit to the original author(s) and the source, provide a link to the Creative Commons licence, and indicate if changes were made. The images or other third party material in this article are included in the article's Creative Commons licence, unless indicated otherwise in a credit line to the material. If material is not included in the article's Creative Commons licence and your intended use is not permitted by statutory regulation or exceeds the permitted use, you will need to obtain permission directly from the copyright holder. To view a copy of this licence, visit http://creativecommons.org/licenses/by/4.0/ The Creative Commons Public Domain Dedication waiver (http://creativecommons.org/publicdomain/zero/1.0/) applies to the data made available in this article, unless otherwise stated in a credit line to the data. 
and consistent protection against infections and diseases related to these HPV types [2].

The World Health Organization (WHO) recognizes the importance of cervical cancer and other HPV-related diseases as global public health problems and reiterates the recommendation that HPV vaccines should be included in national immunization programmes [3]. WHO recommends vaccination for girls aged $9-13$ years as this is the most cost-effective public health measure against cervical cancer [4]. By October 2019, 98 countries introduced HPV vaccines through national immunisation programmes [5]. The population-level effect of HPV vaccination programmes is expected to vary substantially between these countries, depending on the vaccine used, implementation strategies applied and vaccination coverage achieved [6].

As the quadrivalent vaccine became available in 2006, HPV vaccination has been introduced in an increasing number of high-income countries, while in low- and middle-income countries the bivalent, or both vaccines are funded. There is high certainty evidence that HPV vaccines protect against cervical precancer (cervical intraepithelial neoplasia grade $2 / 3$ and above) in adolescent girls and young women who are vaccinated between aged 15 to 26 [7], and growing evidence support that introduction of HPV vaccines reduces HPV related diseases, including precancerous or dysplastic lesions [8-11]. By achieving high vaccination coverage (> 80\%) in girls, the risk of HPV infection for boys can also be reduced and its elimination could also be achieved [12]. Moreover, the quadrivalent vaccine has also been found to be highly effective in preventing genital lesions associated with infection with HPV 6, 11, 16, or 18 in men [13]. Therefore, several countries, such as the United States of America (USA), Australia, Switzerland, Austria, and Canada, have started to vaccinate boys as well as the quadrivalent vaccination prevents genital cancers and $\mathrm{GW}$ in both males and females.

Although GW are usually not referred to be a serious condition, the loss of quality of life of patients, physical symptoms such as pruritus and pain, and the impact on sexuality can be addressed as significant issues [14].

In the present work our aim was to summarize the available evidence on the efficacy of the quadrivalent HPV vaccine in preventing GW by conducting a metaanalysis. To achieve this, the following PICO (patients, intervention, comparison, outcome) format was applied: P: human population; I: quadrivalent HPV vaccine; C: no vaccine/placebo and $\mathrm{O}$ : reduced incidence/prevalence of GW.

\section{Methods}

The present meta-analysis was performed using the Preferred Reporting Items for Systematic Review and Meta-
Analyses protocols (PRISMA protocol) [15]. This metaanalysis protocol was registered with the International Prospective Register of Systematic Reviews (PROSPERO), registration number: CRD42018095030.

\section{Search strategy and selection criteria}

We conducted a systematic search in three electronic databases from inception up to 13th of January, 2020, without language restrictions. The following search queries were used: ("genital wart"[All Fields] OR "anogenital wart"[All Fields] OR ("condylomata acuminata" [MeSH Terms] OR ("condylomata"[All Fields] AND "acuminata"[All Fields]) OR "condylomata acuminata"[All Fields] OR "condyloma" [All Fields]) OR "condyloma acuminatum"[All Fields]) AND ("HPV vaccine"[All Fields] OR "HPV vaccination"[All Fields] OR "human papillomavirus vaccine"[All Fields] OR "human papillomavirus vaccination" [All Fields] OR ("human papillomavirus recombinant vaccine quadrivalent, types 6,11,16,18”[MeSH Terms] OR "gardasil"[All Fields])) AND "humans"[MeSH Terms] for PubMed; ("genital wart" OR "anogenital wart" OR condyloma OR "condyloma acuminatum") AND ("hpv vaccine" OR "hpv vaccination" OR "human papillomavirus vaccine" OR "human papillomavirus vaccination" OR "gardasil") AND [humans]/lim AND ([article]/lim OR [article in press]/lim OR [conference abstract]/lim OR [conference paper]/lim OR [conference review]/lim OR [review]/lim) for Embase and ("genital wart" OR "anogenital wart" OR condyloma OR "condyloma acuminatum") AND ("HPV vaccine" OR "HPV vaccination" OR "human papillomavirus vaccine" OR "human papillomavirus vaccination" OR Gardasil) for Cochrane Trials. We identified relevant studies by reviewing titles and abstracts, and the reference lists of relevant articles were also searched to reveal all relevant studies.

We included RCTs and time-trend ecological studies which assessed the effectiveness of the quadrivalent HPV vaccine in the frequency (incidence/prevalence) of GW. In the RCTs, HPV vaccines were administered only to females, except one RCT, where Japanese males were received HPV vaccine or placebo [16]. Similarly to most of included RCTs, only women were vaccinated in ecological studies, but the whole population were included - because the researchers examined the indirect effect of the vaccine on men as well - except in one study [17], where only females were involved. Articles were eligible for inclusion if they provided data about the incidence of GW in the vaccinated and placebo group (RCT studies) or if they assessed the population-level effect of the quadrivalent HPV vaccination by comparing the prevalence of GW between the pre- and post-vaccination periods (time-trend ecological studies).

We excluded studies with the following characteristics: just the bivalent vaccine was used; or bivalent and 
quadrivalent vaccines were used alternatively; or the quadrivalent HPV vaccination was administered in the framework of private care; or the frequency of GW was studied during the post-vaccination period and the comparison of pre- and post-vaccination period was not included. The present analysis included only articles where the absolute number of GW is available. Narrative reviews, mathematical modelling studies, conference abstracts, and conference papers were also excluded.

\section{Study selection}

The EndNote X7.4 software package was used for record management. After removing duplicates, the remaining records were screened for eligibility by two authors (AL, AS) based on the title and abstract of the published original papers. The eligibility of full texts of the remaining records was assessed by two reviewers independently. Disagreement between reviewers was resolved by discussion or, if it was necessary, by consulting with a third reviewer (ZSM).

\section{Risk of bias assessment}

The quality of the studies was assessed independently by two authors (AL, AS). We carried out a risk of bias assessment of RCTs using tools proposed by Cochrane for RCTs [18]. This tool assesses the risk of bias based on five domains: selection bias, performance bias, detection bias, attrition bias and reporting bias. For ecological studies the risk of bias was assessed using the method of Drolet and his colleagues [6]. We evaluated the risk of bias using three domains: selection bias, information bias, and risk of confounding.

\section{Data extraction}

Data extraction was conducted independently by two investigators (AL, AS). In case of disagreement concerning the inclusion of studies and extracted data, a third investigator (ZSM) was involved to resolve discrepancies.

In RCTs, the data for primary analysis were collected from a per-protocol susceptible population of women, who received all three doses of vaccination and who had no virological evidence of the relevant HPV types through 7 months after administration of the third dose. In RCTs, we collected information about the number of GW in the vaccinated and placebo groups. Afterwards the number of countries included in the given RCT, the length of the follow-up period, the age of the participants and the lifetime number of their sexual partners were also extracted.

In the included ecological trials our primary outcome was the number of GW in the pre- and post-vaccination periods. Secondly, we collected information about the introduction year of the vaccine in the certain country, some details about the vaccination programme, the demographic characteristics of the participants and the duration of the pre- and post-vaccination periods.

\section{Data analysis}

For data synthesis we used the methods recommended by the working group of the Cochrane Collaboration. In the meta-analysis, odds ratios (ORs) as well as their 95\% confidence intervals (CI) were calculated from the original data of the articles and were visualized in forestplots. Subgroup-analysis was done within ecological studies according to gender and according to age groups (younger or older than 21). In case of gender we applied meta-regression as well. Depending on data quality, the random effect model by DerSimonian and Laird [19] was used. The heterogeneity was tested also with Q-test statistic and I-squared. A leave-one-out sensitivity analysis was performed by iteratively removing one study at a time to confirm that our findings were not driven by any single study. Statistical analyses were carried out using the STATA software version 15.0.

\section{Assessment of publication bias}

We evaluated the presence of publication bias using the funnel plot graph. We also performed Copas selection model to test the publication bias, calculations were performed with R (V. 3.5.2) package metasens (V. 0.4-0).

\section{Assessment of quality of evidence}

Strength of the overall body of evidence was assessed using the Grading of Recommendations, Assessment, Development and Evaluation (GRADE) approach. Quality of a body of evidence involves consideration of risk of bias, heterogeneity, directness of evidence, precision of effect and risk of publication bias, as described in Section 12.2.2 of the Cochrane Handbook for Systematic Reviews of Interventions [18]. The quality of evidence was judged as "high", "moderate", "low", or "very low".

\section{Results}

\section{Selection of studies}

Literature searches were performed in PubMed, Embase, and Cochrane Library, where altogether 1862 references were identified. After removing duplicates, and reading the titles and abstracts, a total of 106 potentially relevant articles remained. Finally, 16 studies (8 RCTs and 8 time-trend analyses) were eligible for inclusion in the meta-analysis with more than 13,000000 participants. All selected studies corresponded only to the quadrivalent vaccine.

The flow chart for identification of relevant studies and the reasons for exclusions are included in Fig. 1. 


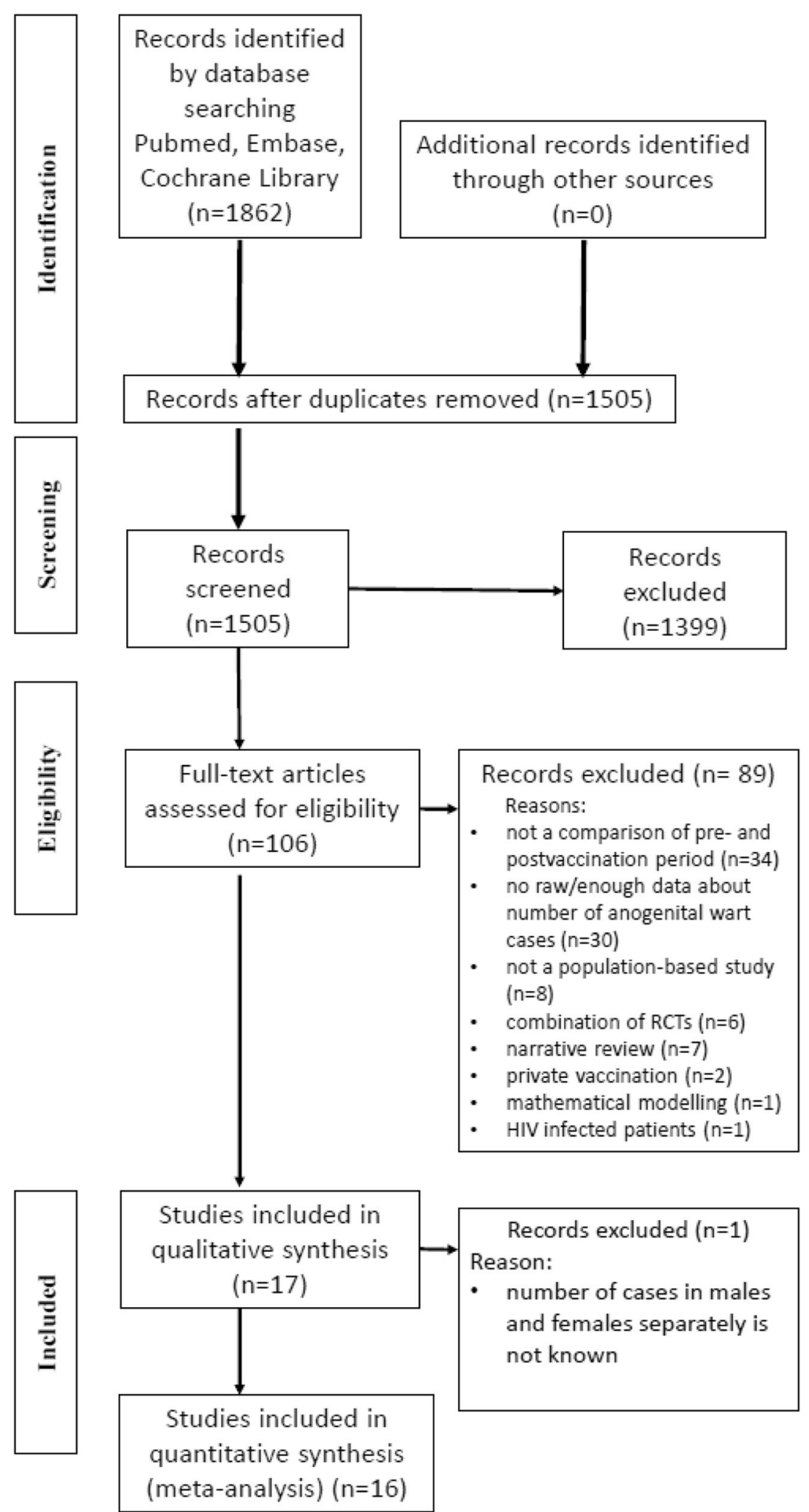

Fig. 1 PRISMA 2009 flow diagram for identification of relevant studies 


\section{Characteristics of the included studies}

Altogether 8 randomised, double-blind, placebocontrolled studies were included in our final quantitative analysis [16, 20-26]. Healthy, non-pregnant women aged between 15 and 26 years with no history of abnormal Pap smear at enrolment were included in seven RCTs, who reported no more than 4 lifetime sexual partners except the Finnish women in Munoz's study [24] where this restriction was not applied. The total number of enrolled women was 20,416 in the vaccinated group and 20,279 in the placebo group. In the Japanese RCT [16] 561 males were in the vaccinated group and 562 males were received placebo. The mean age of the participants is shown in Table 1. Participants were vaccinated either with the quadrivalent HPV (types 6, 11, 16 and 18) vaccine (vaccinated group) or with placebo (aluminium hydroxyphosphate sulphate adjuvant) by three doses of intramuscular injection. The vaccine was composed of

Table 1 Characteristics of the studies (RCTs) included in the meta-analysis

\begin{tabular}{|c|c|c|c|c|c|c|c|c|c|}
\hline \multirow{4}{*}{$\begin{array}{l}\text { First } \\
\text { author (year) }\end{array}$} & \multirow{4}{*}{$\begin{array}{l}\text { Study } \\
\text { type }\end{array}$} & \multirow[t]{4}{*}{ Countries } & \multirow{4}{*}{$\begin{array}{l}\text { Average follow- } \\
\text { up period }\end{array}$} & \multicolumn{4}{|c|}{ Patient characteristics } & \multirow{4}{*}{$\begin{array}{l}\text { Number of } \\
\text { cases/number } \\
\text { of patients } \\
\text { Vaccinated } \\
\text { group }\end{array}$} & \multirow{4}{*}{$\begin{array}{l}\text { Number } \\
\text { of cases/number } \\
\text { of patients } \\
\text { Placebo group }\end{array}$} \\
\hline & & & & \multicolumn{3}{|l|}{ Age (years) } & \multirow{3}{*}{$\begin{array}{l}\text { Number } \\
\text { of sexual partners }\end{array}$} & & \\
\hline & & & & \multicolumn{2}{|l|}{ Mean } & \multirow[t]{2}{*}{ Range } & & & \\
\hline & & & & $\begin{array}{l}\text { Vaccinated } \\
\text { group }^{\mathbf{a}}\end{array}$ & $\begin{array}{l}\text { Placebo } \\
\text { group }^{\mathbf{b}}\end{array}$ & & & & \\
\hline $\begin{array}{l}\text { Garland } \\
\text { (2007) [20] }\end{array}$ & $\mathrm{RCT}$ & $\begin{array}{l}16 \text { countries from Asia } \\
\text { Pacific, Europe, North- } \\
\text { Central- and South } \\
\text { America }\end{array}$ & 3 years & $20.2 \pm 1.8$ & $\begin{array}{l}20.3 \pm \\
1.8\end{array}$ & $16-24$ & $<4$ & $0 / 2261$ & $48 / 2279$ \\
\hline $\begin{array}{l}\text { Dillner } \\
\text { (2010) [21] }\end{array}$ & $\mathrm{RCT}$ & $\begin{array}{l}24 \text { countries from } \\
\text { North America, Latin } \\
\text { America, Europe, Asia } \\
\text { Pacific }\end{array}$ & 42 months & 20 & & $16-26$ & $<4$ & $2 / 6718$ & $186 / 6647$ \\
\hline $\begin{array}{l}\text { Majewski } \\
(2009)[22]\end{array}$ & $\mathrm{RCT}$ & $\begin{array}{l}\text { Austria, Czech Republic, } \\
\text { Denmark, England, } \\
\text { Finland, France, } \\
\text { Germany, Greece, } \\
\text { Iceland, Ireland, Italy, } \\
\text { Norway, Poland, } \\
\text { Portugal, Russian } \\
\text { Federation, Spain, and } \\
\text { Sweden. }\end{array}$ & 36 months & 19.7 & & $16-24$ & $\leq 4$ & $1 / 4059$ & $90 / 4057$ \\
\hline $\begin{array}{l}\text { Villa (2006) } \\
\text { [23] }\end{array}$ & $\mathrm{RCT}$ & $\begin{array}{l}\text { Brazil, Nordic countries, } \\
\text { Finland, Sweden, } \\
\text { Norway }\end{array}$ & 60 months & 20.2 & 20.0 & $16-23$ & $\leq 4$ & $0 / 214$ & 20/209 \\
\hline $\begin{array}{l}\text { Munoz } \\
(2010) \text { [24] }\end{array}$ & $\mathrm{RCT}$ & $\begin{array}{l}\text { Australia, Austria, Brazil, } \\
\text { Canada, Colombia, } \\
\text { Czech Republic, } \\
\text { Denmark, Finland, } \\
\text { Germany, Hong Kong, } \\
\text { Iceland, Italy, Mexico, } \\
\text { New Zealand, Norway, } \\
\text { Peru, Poland, Puerto } \\
\text { Rico, Russia, Singapore, } \\
\text { Sweden, Thailand, the } \\
\text { United Kingdom, } \\
\text { United States }\end{array}$ & 3,6 years & $?$ & $?$ & $15-26$ & $\begin{array}{l}<4 \text { except } \\
\text { Finnish women }\end{array}$ & 4/4689 & $138 / 4735$ \\
\hline $\begin{array}{l}\text { Perez (2008) } \\
\text { [25] }\end{array}$ & $\mathrm{RCT}$ & $\begin{array}{l}\text { Brazil, Mexico, } \\
\text { Colombia, Costa Rica, } \\
\text { Guatemala, Peru }\end{array}$ & $?$ & $19.8 \pm 3.0$ & $\begin{array}{l}20.3 \pm \\
2.2\end{array}$ & $9-24$ & $\leq 4$ & $0 / 2075$ & 9/1976 \\
\hline $\begin{array}{l}\text { Yoshikawa } \\
\text { (2013) [26] }\end{array}$ & $\mathrm{RCT}$ & Japan & 23 months & $22.7 \pm 2.1$ & $\begin{array}{l}22.9 \pm \\
2.1\end{array}$ & $18-26$ & $\leq 4$ & $2 / 400$ & $7 / 376$ \\
\hline $\begin{array}{l}\text { Mikamo } \\
\text { (2019) [16] }\end{array}$ & $\mathrm{RCT}$ & Japan & 36 months & $22.6 \pm 2.1$ & $\begin{array}{l}22.6 \pm \\
2.0\end{array}$ & $18-27$ & $17-26$ & $0 / 561$ & $1 / 562$ \\
\hline
\end{tabular}

$R C T$ : randomised controlled trial

${ }^{\mathrm{a}}$ : vaccine = quadrivalent HPV vaccine (HPV types $6,11,16,18$ )

b: placebo = aluminium hydroxyphosphate sulphate adjuvant 
$20 \mu \mathrm{g}$ of HPV 6, $40 \mu \mathrm{g}$ of HPV 11, $40 \mu \mathrm{g}$ of HPV 16 and $20 \mu \mathrm{g}$ of HPV 18, formulated with $225 \mu \mathrm{g}$ of aluminium adjuvant. The clinical follow-up periods were between 23 months and 60 months in RCTs. We included the per-protocol population who received all three doses of vaccine or placebo and were seronegative and PCR negative for the relevant HPV types at day 1.

Additionally, 8 time-trend analyses [17, 27-33] were included in the present meta-analysis. Five studies [2731] were performed in Australia, one [17] in Belgium, one [32] in England, and one [33] in the USA (Table 2). The Belgian studies assessed the population-level effect of the quadrivalent HPV vaccination on $\mathrm{GW}$ in women [17] and the other 7 articles [27-33] measured the number of GW cases also in men to investigate the herd effect of the vaccine. The quadrivalent vaccine was introduced as a school-based programme in Australia, in 2007. In Belgium, HPV vaccines were reimbursed for women aged 12 to 18 years since 2007. In England, HPV vaccination programme was introduced in 2008, since 2012 the quadrivalent vaccine has been used for females. In the USA, HPV vaccination has been recommended both for girls and boys aged 11-12 years with catch-up vaccination through age 26 years. The investigators compared the number of GW between the pre- and postvaccination periods and they evaluated the real-life benefit of the introduction of the quadrivalent HPV vaccine on GW at population level.

\section{Effectiveness of quadrivalent HPV vaccine on GW}

According to the results of RCTs, the quadrivalent HPV vaccine significantly reduced the risk of GW (pooled $\mathrm{OR}=0.03$, 95\% CI: 0.01-0.09) in healthy women as shown in Fig. 2a. Although high heterogeneity was reported across studies (I-squared $=53.6 \%, p=0.035$ ).

In time-trend analyses (Fig. 2b), the number of GW events decreased significantly, by $64 \%$ (pooled $\mathrm{OR}=0.36$, CI $95 \%=0.26-0.51)$ in the post-vaccination period in women. In young men, despite the fact, that they were not vaccinated, the reduction in GW cases was also significant (pooled $\mathrm{OR}=0.69,95 \% \mathrm{CI}=0.61-0.78$ ), although not as prominent as seen in women. The overall population effect of quadrivalent vaccine was protective against GW (pooled $\mathrm{OR}=0.52,95 \% \mathrm{CI}=0.46-0.58$ ). The heterogeneity was considerable both in articles involving women (I-squared $=98.2 \%, \quad p<0.001$ ) and men (Isquared $=92.7 \%, \mathrm{p}<0.001)$.

We performed a leave-one-out sensitivity analysis by iteratively removing one study at a time and recalculating the summary OR. The summary ORs remained stable both in RCTs (Fig. 3a) and in ecological studies (Fig. 3b), indicating that our results were not driven by any single study and that similar results could be obtained after excluding one study.
In subgroup analysis, when the age-groups were separated at 21 years, in women under 21 years of age, the number of GW events decreased significantly by $67 \%$ (pooled OR $=0.33,95 \% \mathrm{CI}=0.17-0.63$ ), in women over 21 years of age, GW reduced less substantially (by 50\%) (pooled OR $=0.50,95 \% \mathrm{CI}=0.32-0.78$ ) (Fig. 4a). In men under 21 years of age, GW reduced significantly by $49 \%$ (pooled $\mathrm{OR}=0.51,95 \% \mathrm{CI}=0.34-0.75$ ) in the postvaccination period, the reduction of $\mathrm{GW}$ was also significant in men over 21 years old (pooled OR $=0.68,95 \%$ $\mathrm{CI}=0.59-0.79$ ) (Fig. 4b).

Based on the results of leave-one-out sensitivity analysis (Fig. 5a, b), removing one study showed similar and consistent result.

Meta-regression also did not show significant difference $(p=0.54)$ among odds ratios of studies (Fig. 6).

\section{Publication bias}

The results of Copas selection model are included as Additional file 1. No publication bias was observed in the analysis of RCTs (A). In the analysis of ecological studies (B) publication bias may occur, but the leaveone-out analysis did not show inconsistent result.

\section{Risk of bias assessment}

Among RCTs only one study [25] was rated as high risk of detection and attrition bias due to the lack of blinded investigation of the samples by pathologists and also to missing outcome data (Fig. 7). The randomization, performance and reporting bias were considered low in the case of all studies. 3 RCTs [21-23] showed unclear selection bias and in article Dillner and co-workers [21] some data might not have been revealed and published (unclear attrition bias).

Most of the time-trend analyses showed high risk of confounding factors such as changes in sexual activity and health-seeking behaviour during the long period of the study, which can potentially cause changes in GW. The majority of studies showed low risk of information bias because GW were diagnosed by physicians except in the study of Dominiak-Felden [17], where a surrogate marker was used as definition of cases. Due to the possible changes of clientele of sexual health services between the pre- and post-vaccination periods, the risk of selection bias was evaluated as unclear or high. Moreover, in two studies $[27,28]$ the vaccination status and the number of doses of HPV vaccines were selfreported, therefore the risk of selection bias was high (Table 3).

\section{Level of evidence assessment}

The GRADE evidence profiles are shown in Table 4. By their very nature, RCTs are considered "high quality" but we downgraded them by 1 because the per-protocol 


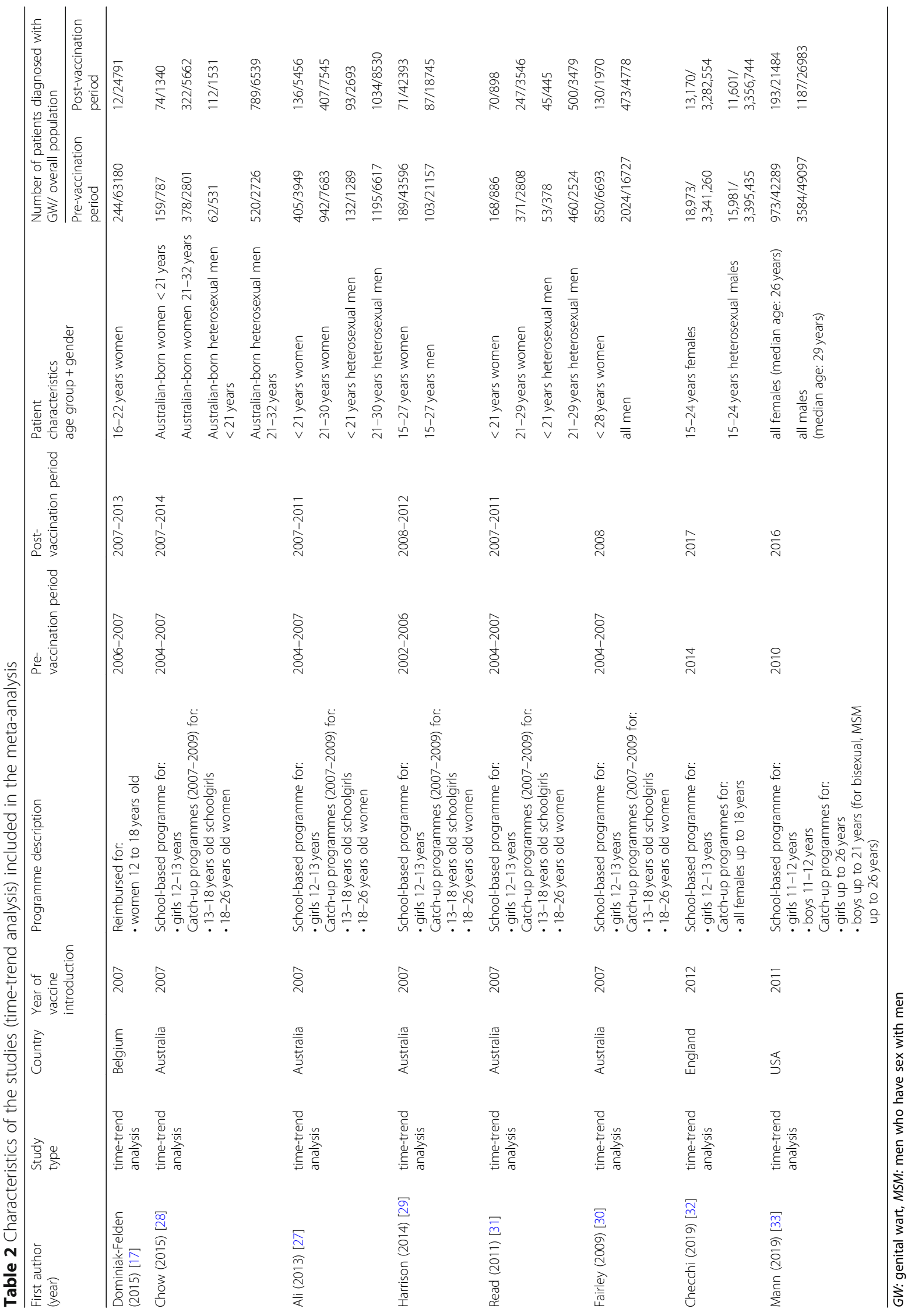




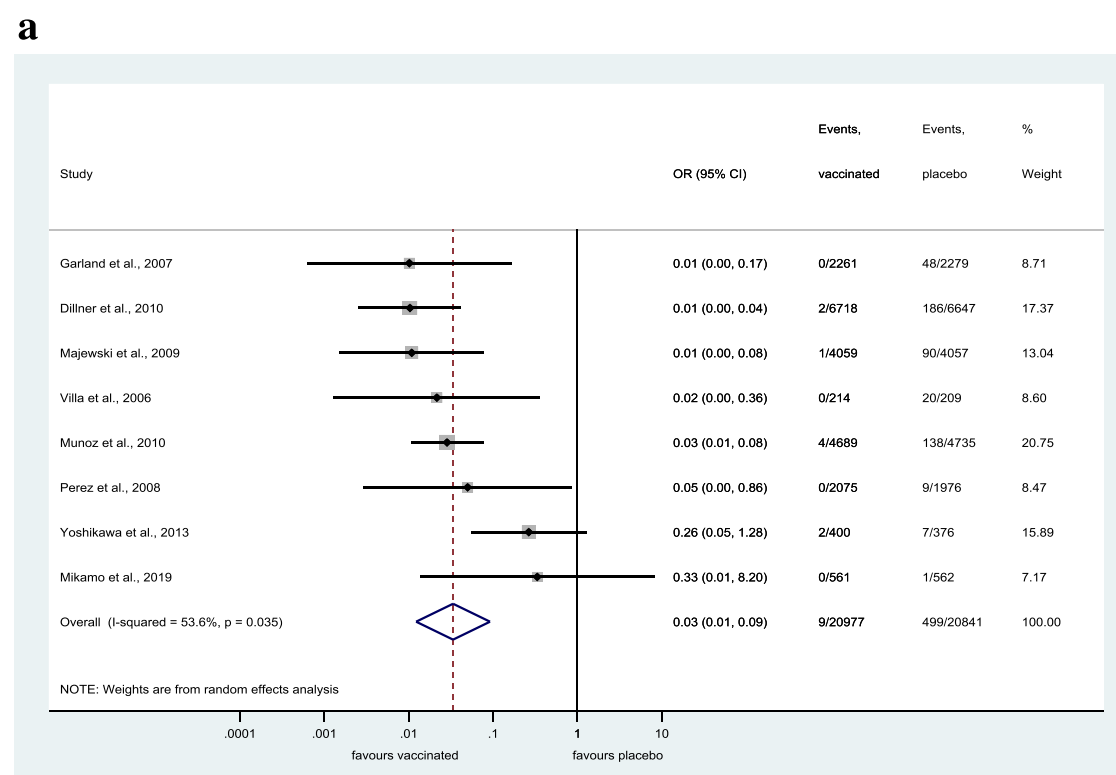

b

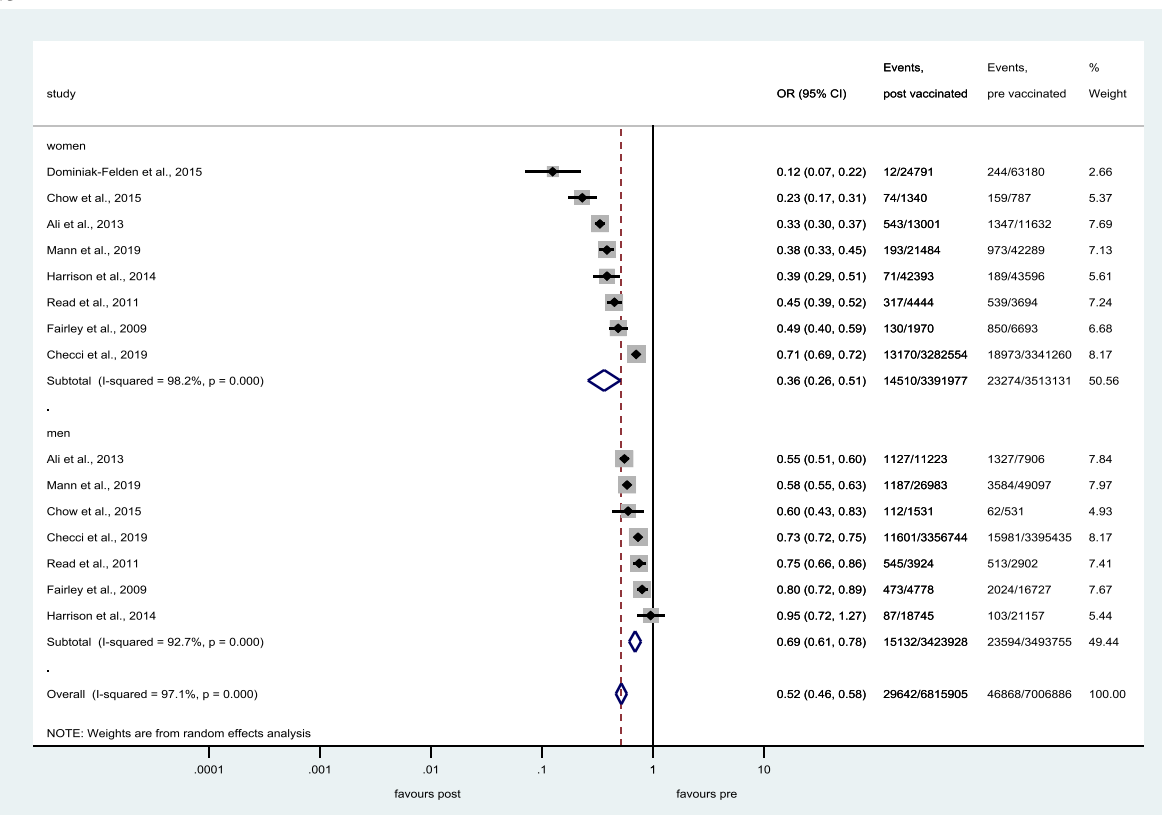

Fig. 2 Forest plot of the effectiveness of HPV quadrivalent vaccine in the prevention of GW in RCTs (a) and ecological studies (b)

population in RCTs does not represent the whole population due to the strict inclusion and exclusion criteria. As a consequence, the GRADE level of evidence can be regarded as moderate for RCTs. The natural "low quality" of time-trend analyses was first down- than upgraded, resulting in "low quality" according to GRADE.

\section{Discussion}

In the present study, we investigated the incidence of GW in healthy women after the administration of quadrivalent HPV vaccination (or placebo) and compared the presence of GW in women and men before and after the administration of the quadrivalent HPV vaccine. Altogether 16 studies (including 8 RCTs) were included in the current meta-analysis. We found that the quadrivalent HPV vaccine is effective in preventing GW in women. According to the results of subgroup analyses, GW reduction was more substantially in women under 21 years of age. Furthermore, a significant herd protection was observed in young men. 
$\mathbf{a}$

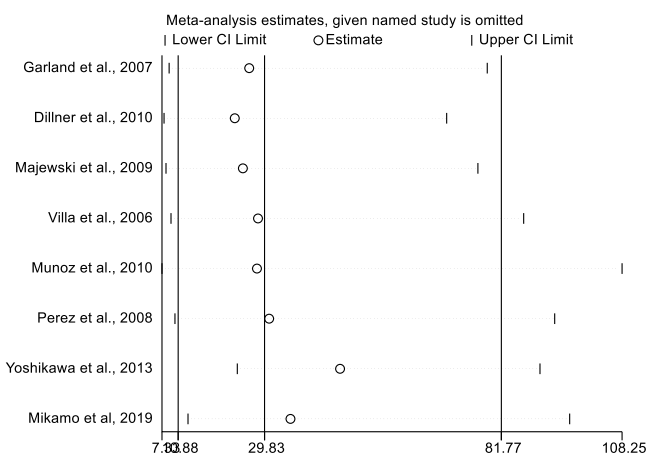

\begin{tabular}{|c|c|c|c|}
\hline Study omitted | & Estimate & {$[95 \%$ Conf. } & Interval] \\
\hline Garland et al., 2007 & 26.45479 & 8.8954601 & 78.675621 \\
\hline Dillner et al., 2010 & 23.296211 & 7.7783518 & 69.772301 \\
\hline Majewski et al., 2009 & 25.075895 & 8.2060919 & 76.62606 \\
\hline Villa et al., 2006 & 28.393034 & 9.3021364 & 86.664429 \\
\hline Munoz et al. 2010 & 28.159111 & 7.3252854 & 108.24636 \\
\hline Perez et al., 2008| & 30.833599 & 10.171365 & 93.469345 \\
\hline Yoshikawa et al., 201 & $3 \mid 46.391293$ & 23.848598 & 90.242287 \\
\hline Mikamo et al, 2019] & 35.515182 & 13.036238 & 96.755539 \\
\hline Combined & 29.830894 & 10.882877 & 81.769027 \\
\hline
\end{tabular}

b

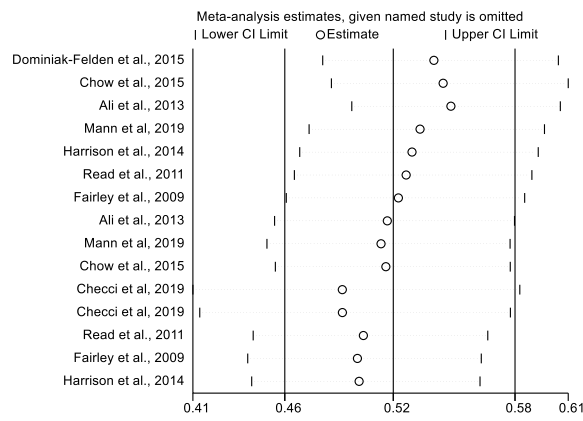

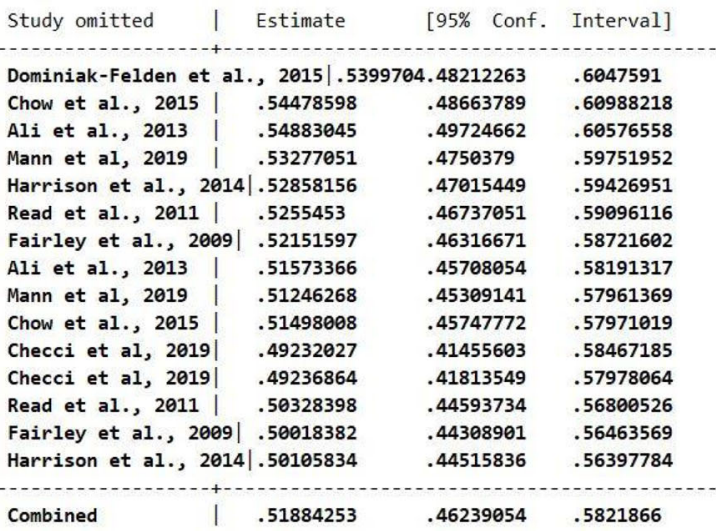

Fig. 3 Results of leave-one-out sensitivity analysis (plot and numbers) in RCTs (a) and in ecological studies (b)The vertical axis shows the omitted study. The horizontal axis represents the odds ratio. Every circle indicates the pooled OR when the left study is omitted in this meta-analysis. The two ends of every broken line represent the respective $95 \%$ confidence interval $(\mathrm{Cl})$ 


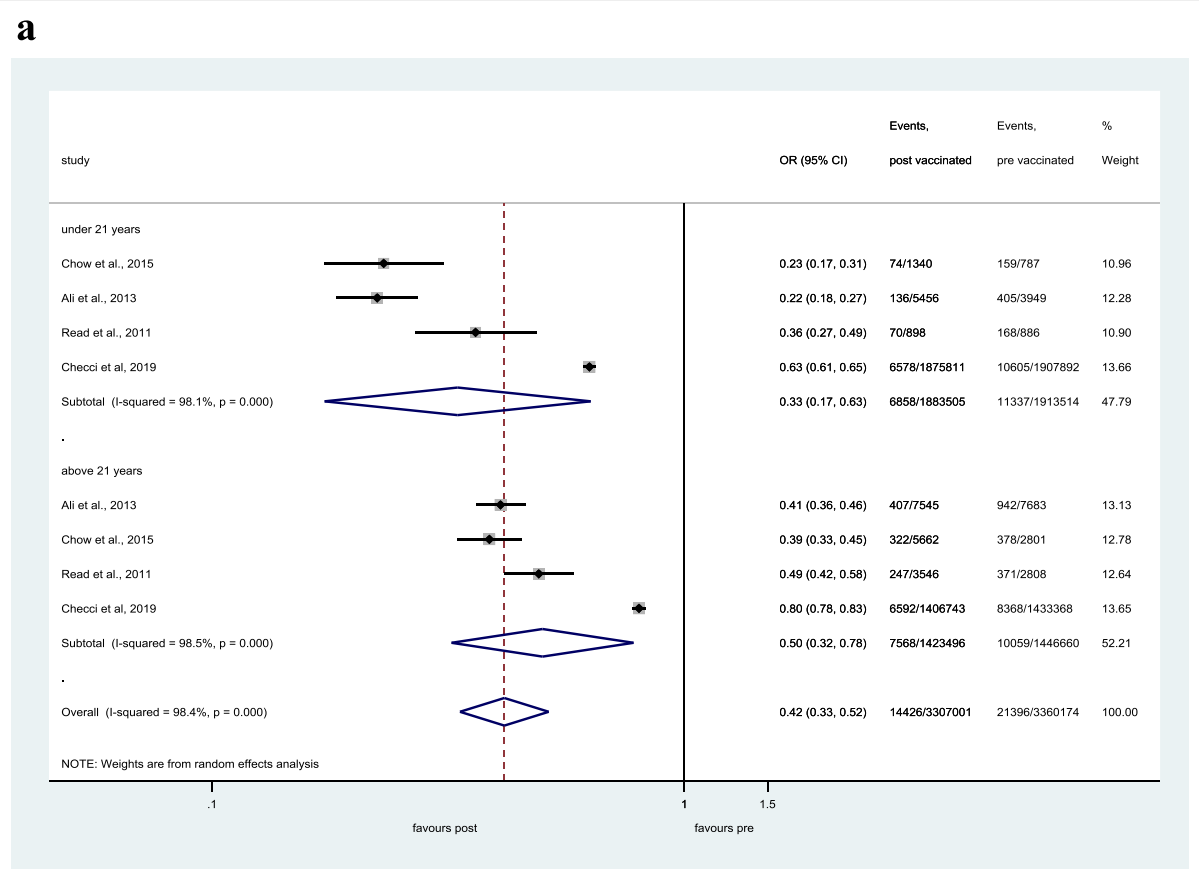

b

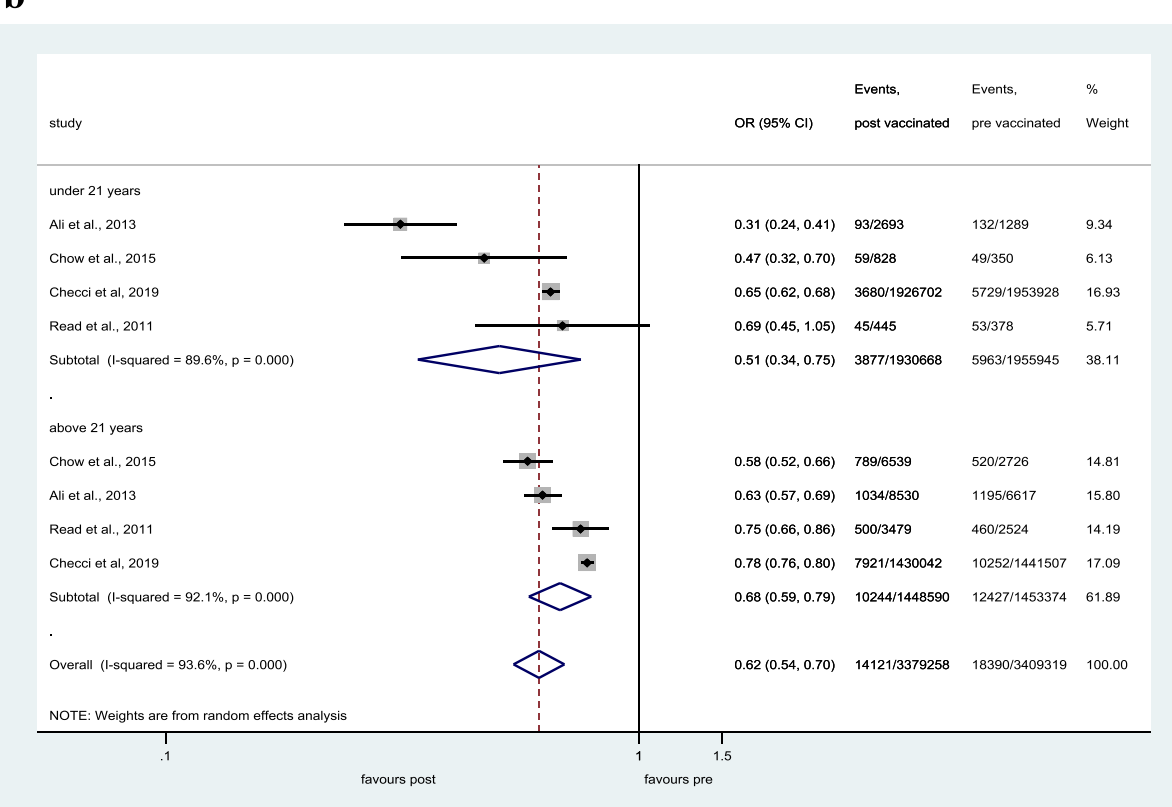

Fig. 4 Subgroup analyses of the changes in GW diagnosis between the pre- and post-vaccination periods in women (a) under 21 years of age and over 21 years of age, and in men (b) under 21 years of age and over 21 years of age

Leave-one-out analysis showed that similar results could be obtained after excluding one study.

RCTs have clearly demonstrated the efficacy of the quadrivalent HPV vaccine in vaccinated persons but not investigated the effects at population level and in men. At population-level, a reduction in the prevalence of GW was reported due to HPV vaccination. In men, we also observed a significant decline in GW, which can most likely be attributed to the indirect protection provided by the vaccination of women by the quadrivalent vaccine. This so called "herd immunity" is the protective effect of the vaccine extending beyond the vaccinated individuals to the unvaccinated ones in the population [34].

Overall, most of the RCTs showed low or unclear risk of bias, therefore, the methodological quality of the trials is acceptable. Ecological studies provide valuable timely 
$\mathbf{a}$

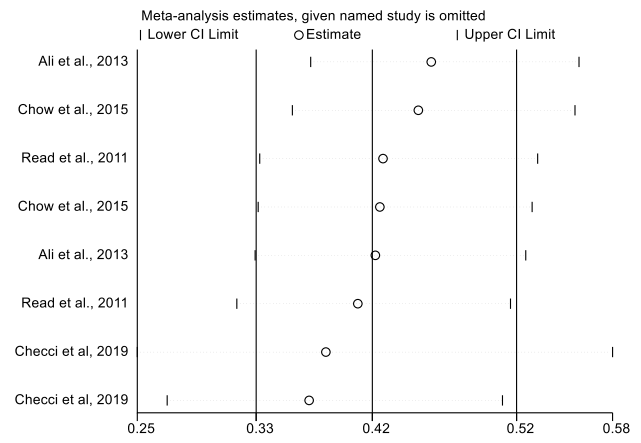

\begin{tabular}{l|lll} 
Study omitted | & Estimate & {$[95 \%$ Conf. } & Interval $]$ \\
\hline Ali et al., 2013 | & .45674011 & .37280825 & .55956793 \\
Chow et al., 2015 | & .44774696 & .36007589 & .55676413 \\
Read et al., 2011 | & .42315283 & .3373467 & .53078431 \\
Chow et al., 2015 | & .42094687 & .3362757 & .52693748 \\
Ali et al., 2013 | & .41783127 & .33413506 & .52249223 \\
Read et al., 2011 | & .40561822 & .32141122 & .51188672 \\
Checci et al, 2019| & .38337925 & .25214204 & .58292401 \\
Checci et al, 2019| & .37173793 & .27293539 & .50630695 \\
\hline Combined & .41572748 & .33486979 & .51610907
\end{tabular}

$\mathbf{b}$

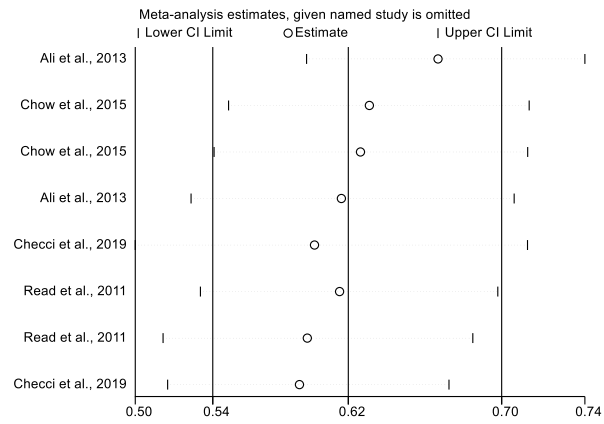

\begin{tabular}{l|lll} 
Study omitted | & Estimate & {$[95 \%$ Conf. } & Interval] \\
\hline Ali et al., 2013 | & .66263372 & .59316921 & .74023306 \\
Chow et al., 2015 | & .62636322 & .55195391 & .71080369 \\
Chow et al., 2015 | & .62165022 & .54428089 & .71001756 \\
Ali et al., 2013 | & .61156499 & .53213078 & .70285678 \\
Checci et al., 2019| & .5973599 & .50264579 & .70992106 \\
Read et al., 2011 | & .61061102 & .53707176 & .69421977 \\
Read et al., 2011 | & .59355789 & .51733333 & .68101346 \\
Checci et al., 2019| & .58941483 & .51974529 & .6684233 \\
\hline Combined & .61521952 & .54360544 & .69626796
\end{tabular}

Fig. 5 Results of leave-one-out sensitivity analysis (plot and numbers) among studies in women (a) and in men (b). The vertical axis shows the omitted study. The horizontal axis represents the odds ratio. Every circle indicates the pooled OR when the left study is omitted in this metaanalysis. The two ends of every broken line represent the respective $95 \%$ confidence interval (Cl) 


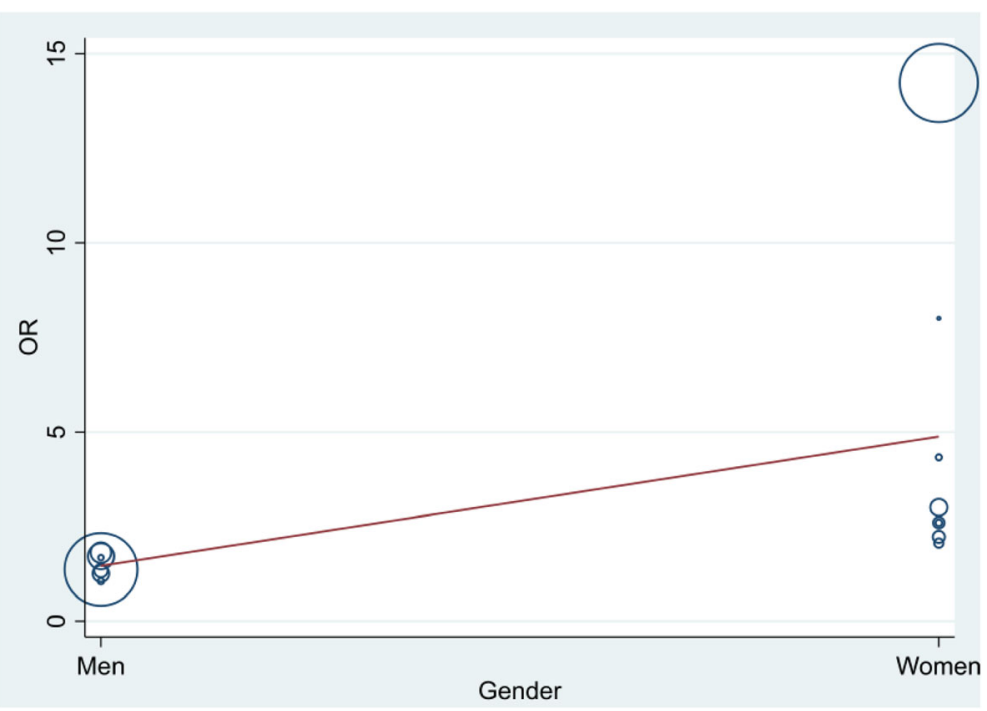

Fig. 6 "Bubble plot" with fitted meta-regression line. OR= odds ratio

information about the population-level effects of HPV vaccination using large populations. However, these studies are vulnerable to carry risk of bias. The possible changes in the clientele and/or in sexual activity or health-seeking behaviour of the clients can modify the diagnosis of GW over time. Despite the unclear/high risk of selection bias and confounding factors, it was important to use the results of time-trend analyses to evaluate the performance of the vaccine under real-life settings to confirm that the efficacy/effectiveness can be seen not exclusively under ideal clinical conditions.

Heterogeneity was moderate in RCTs and considerable in time-trend analyses. In the study of Yoshikawa and co-workers only one country was covered in contrast to the other RCTs, in which several countries were involved. In addition, the follow-up period was much shorter in the Japanese study, which could explain the moderate heterogeneity among RCTs. Moreover, the ecological studies were performed in different countries, and the difference in vaccination coverage, sexual behaviour, length of pre- and post-vaccination periods, or source of study data could also be a cause of heterogeneity.

Our findings are consistent with previous reviews and meta-analyses, where it was also found that the prevalence of GW decreased significantly in vaccinated girls $[6,35,36]$, and the quadrivalent prophylactic vaccination could prevent HPV infection in men and women [37]. However, high heterogeneity was found in the case of time trend ecological studies, thus, our results should be interpreted with caution.

Gardasil ${ }^{\circ}$ has been the vaccine of choice worldwide. It has been chosen by health authorities in the United States, Australia, New Zealand, Canada, Switzerland,
Italy, Spain, and Sweden for regional or national vaccination programmes against cervical cancer. The United Kingdom substituted the bivalent vaccine with the quadrivalent one in 2012, since the government clarified that the aim is to protect girls against the types of HPV that cause cervical cancer and those that cause GW [38]. A study from Australia shows that cases of GW have nearly disappeared since 2007, when the national vaccination programme against cervical cancer using Gardasil $^{\circ}$ was introduced [31]. In NewZealand the relative risk of GW diagnosis decreased after the introduction of the quadrivalent HPV vaccination in late 2008 [39]. In Spain, there was a decline in GW when female subjects were vaccinated with quadrivalent HPV vaccine, although the bivalent vaccine showed no efficacy against GW [40].

To the best of our knowledge, our work is the first meta-analysis related to GW which is based on the results of both RCTs and time-trend analyses, and carried out a combined analysis in men and women. The advantage of this paper is the high number of participants involved in ecological studies and consequently in this meta-analysis.

However, there are some limitations of this study. First, particularly, the per-protocol population in RCTs is not entirely representative of the general population of women because of the exclusion and inclusion criteria of the trials (for example, low lifetime number of sex partners, no past history of abnormal Pap test or external genital abnormality). Therefore, our results cannot be generalized to other populations with different background risks. Second, in RCTs, many participants from a lot of countries were involved. We tried to come into contact with several authors to get raw data, but the 


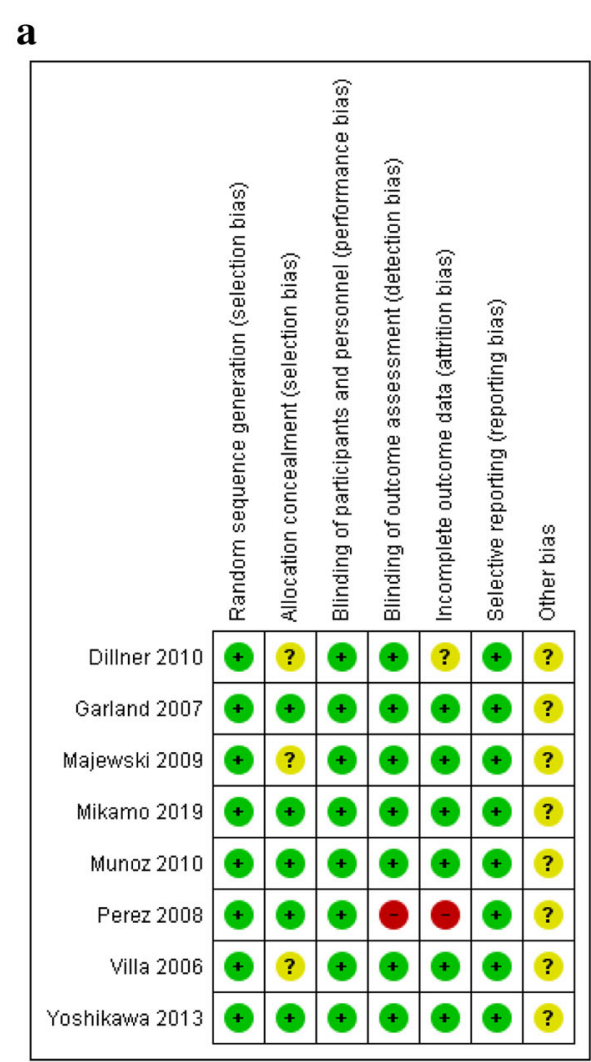

$\mathbf{b}$

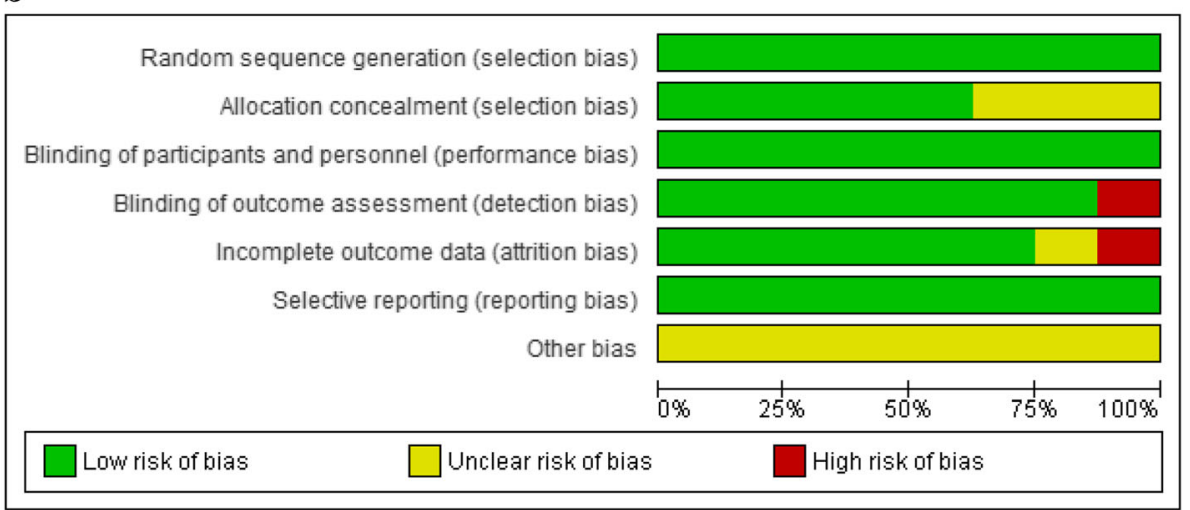

Fig. 7 Risk of bias summary: review of authors' judgement on each risk of bias item for each included RCT study (a); and risk of bias graph: review of authors' judgement on each risk of bias item, presented as percentages across all included RCT studies (b)

response rate was very low. Thus we cannot state that the actual subsets involved in the different included studies differed totally, but it may not entail extreme distortions. Third, we had to exclude some reports, because we were unable to extract the necessary information from them (mainly the absolute number of genital warts in the pre- and postvaccination periods). Fourth, since our aim was to evaluate the population-level effect of the vaccine, we included time-trend analyses despite the high risk of bias. In addition, this meta-analysis covers time-trend analyses mainly from Australia (1 from England, 1 from the USA, 1 from Belgium and 5 from Australia). Fifth, those articles in which HPV vaccine was administered in the framework of private care, and it was not covered by the National Health Insurance, were excluded, thus the present analysis does not take into account the effect of vaccines that were purchased. We think, that the persons who purchased the HPV vaccine may have different socioeconomic status and sexual habits than those people who were vaccinated in the 
Table 3 Risk of bias in time-trend analyses

\begin{tabular}{|c|c|c|c|}
\hline $\begin{array}{l}\text { First } \\
\text { author } \\
\text { (year) }\end{array}$ & $\begin{array}{l}\text { Risk of selection bias: changes in the study } \\
\text { population characteristics between the pre- } \\
\text { and post-vaccination periods }\end{array}$ & $\begin{array}{l}\text { Risk of information bias: errors in the } \\
\text { identification of HPV+ during the pre- and } \\
\text { post-vaccination period (data source, genital } \\
\text { wart case definition, outcome used) }\end{array}$ & $\begin{array}{l}\text { Risk of confounding: } \\
\text { changes in HPV infection between the } \\
\text { pre- and post-vaccination periods } \\
\text { could be diluted/exacerbated by other } \\
\text { variables }\end{array}$ \\
\hline $\begin{array}{l}\text { Dominiak- } \\
\text { Felden } \\
\text { (2015) } \\
{[17]}\end{array}$ & $\begin{array}{l}\text { High } \\
\text { Some people possibly may have been } \\
\text { vaccinated without reimbursement (risk of } \\
\text { misclassification), imiquimod agreement was } \\
\text { used as the date of vaccination. }\end{array}$ & $\begin{array}{l}\text { High } \\
\text { A surrogate marker (imiquimod agreement) } \\
\text { was used as definition of genital wart cases (risk } \\
\text { of underestimation). }\end{array}$ & $\begin{array}{l}\text { High } \\
\text { Different sexual behaviours between } \\
\text { vaccinated and unvaccinated women. }\end{array}$ \\
\hline $\begin{array}{l}\text { Chow } \\
(2015) \\
{[28]}\end{array}$ & $\begin{array}{l}\text { High } \\
\text { Possible changes in the clientele of the sexual } \\
\text { health services between the periods. } \\
\text { Self-reported vaccination status and the } \\
\text { number of doses of HPV vaccine. }\end{array}$ & $\begin{array}{l}\text { Low } \\
\text { Clinical diagnosis by clinicians. }\end{array}$ & $\begin{array}{l}\text { High } \\
\text { Clients at sexual health service have } \\
\text { higher risk of sexually transmissible } \\
\text { infections. }\end{array}$ \\
\hline $\begin{array}{l}\text { Ali (2013) } \\
{[27]}\end{array}$ & $\begin{array}{l}\text { High } \\
\text { Possible changes in the clientele of the sexual } \\
\text { health services between the periods. } \\
\text { Self-reported vaccination status and the } \\
\text { number of doses of HPV vaccine. }\end{array}$ & $\begin{array}{l}\text { Low } \\
\text { Genital warts are directly diagnosed by } \\
\text { physicians. }\end{array}$ & $\begin{array}{l}\text { High } \\
\text { Changes in sexual activity, health } \\
\text { seeking behaviour could potentially } \\
\text { cause changes in genital wart } \\
\text { frequency over time. }\end{array}$ \\
\hline $\begin{array}{l}\text { Harrison } \\
(2014) \\
{[29]}\end{array}$ & $\begin{array}{l}\text { Unclear } \\
\text { Some women from the vaccination eligible } \\
\text { group may be included with non-vaccine eli- } \\
\text { gible women due to the change in patient } \\
\text { age. }\end{array}$ & $\begin{array}{l}\text { Low } \\
\text { Genital wart diagnosis by physicians. }\end{array}$ & $\begin{array}{l}\text { High } \\
\text { Change in sexual risk behaviour. }\end{array}$ \\
\hline $\begin{array}{l}\text { Read } \\
(2011) \\
{[31]}\end{array}$ & $\begin{array}{l}\text { Unclear } \\
\text { Possible changes in the clientele of the } \\
\text { Melbourne Sexual Health Centre. }\end{array}$ & $\begin{array}{l}\text { Low } \\
\text { Genital wart diagnosis by physicians. }\end{array}$ & $\begin{array}{l}\text { Unclear } \\
\text { Possible HPV infection of } 21-29 \text { years } \\
\text { women before the vaccination. }\end{array}$ \\
\hline $\begin{array}{l}\text { Fairley } \\
(2009) \\
{[30]}\end{array}$ & $\begin{array}{l}\text { Unclear } \\
\text { Possible changes in the clientele of the } \\
\text { Melbourne Sexual Health Centre. }\end{array}$ & $\begin{array}{l}\text { Low } \\
\text { Genital wart diagnosis by physicians. }\end{array}$ & $\begin{array}{l}\text { Unclear } \\
\text { Boys aged 9-15 years could be } \\
\text { prescribed the vaccine privately. }\end{array}$ \\
\hline $\begin{array}{l}\text { Checchi } \\
\text { (2019) } \\
\text { [32] }\end{array}$ & $\begin{array}{l}\text { Unclear } \\
\text { Inability to link anogenital wart diagnoses to } \\
\text { individual vaccination status. }\end{array}$ & $\begin{array}{l}\text { Low } \\
\text { Genital wart diagnosis by physicians. }\end{array}$ & $\begin{array}{l}\text { Unclear } \\
\text { Patients could attend elsewhere for } \\
\text { treatment of anogenital wart. }\end{array}$ \\
\hline $\begin{array}{l}\text { Mann } \\
(2019) \\
{[33]}\end{array}$ & $\begin{array}{l}\text { Unclear } \\
\text { Patients' vaccination status is unknown. }\end{array}$ & $\begin{array}{l}\text { Low } \\
\text { Genital wart diagnosis by physicians. }\end{array}$ & $\begin{array}{l}\text { Unclear } \\
\text { Patients with anogenital wart could } \\
\text { choose to seek care elsewhere. }\end{array}$ \\
\hline
\end{tabular}

Table 4 Rating the quality of evidence using the GRADE methodology

\begin{tabular}{|c|c|c|c|c|c|c|}
\hline $\begin{array}{l}\text { Num-ber of } \\
\text { studies }\end{array}$ & Study design & $\begin{array}{l}\text { Initial level of evi- } \\
\text { dence }\end{array}$ & $\begin{array}{l}\text { Evidence } \\
\text { components }\end{array}$ & $\begin{array}{l}\text { Downgrade/upgrade of } \\
\text { evidence }\end{array}$ & Notes & $\begin{array}{l}\text { Final level of } \\
\text { evidence }\end{array}$ \\
\hline \multirow[t]{5}{*}{8} & \multirow[t]{5}{*}{$\mathrm{RCT}$} & \multirow[t]{5}{*}{ high } & Risk of bias & - & - & \multirow{5}{*}{$\begin{array}{l}\oplus \oplus \oplus O \\
\text { MODERATE }\end{array}$} \\
\hline & & & Heterogeneity & - & - & \\
\hline & & & Indirectness & downgrade by 1 & $\begin{array}{l}\text { groups with different } \\
\text { background risks }\end{array}$ & \\
\hline & & & Imprecision & - & - & \\
\hline & & & Publication bias & - & - & \\
\hline \multirow[t]{5}{*}{8} & \multirow{5}{*}{$\begin{array}{l}\text { time-trend } \\
\text { analysis }\end{array}$} & \multirow[t]{5}{*}{ low } & Risk of bias & - & - & \multirow{5}{*}{$\begin{array}{l}\oplus \oplus O O \\
\text { LOW }\end{array}$} \\
\hline & & & Heterogeneity & downgrade by 1 & low $p$ value & \\
\hline & & & Indirectness & - & - & \\
\hline & & & Imprecision & upgrade by 1 & $\begin{array}{l}\text { high number of participants, } \\
\text { narrow } \mathrm{Cl}\end{array}$ & \\
\hline & & & Publication bias & - & - & \\
\hline
\end{tabular}


framework of national/school-based programme, therefore the inclusion of privately vaccinated persons may cause a distortion on the outcome of the study.

\section{Conclusions}

The results from RCTs and time-trend analyses - representing more than 13,000 000 participants - have shown that the quadrivalent HPV vaccine is highly effective in preventing HPV 6/11 related GW both in women and men which gives an additional value to the application of this type of vaccine. Our meta-analysis provides upto-date information for the public about the effectiveness of HPV vaccination. Teenagers and their parents should acquire better knowledge about HPV infection and prevention. This is of very high importance, because rumours about vaccine safety have been one of the principal obstacles for the acceptance of HPV vaccination by the public. Despite the early implementation of national vaccination programs, in the majority of developed countries coverage rates remain unsatisfactory [41].

Furthermore, the present work provides reliable information for obstetrician-gynaecologists and other health care providers who should raise the attention of parents and patients for the benefits of HPV vaccination and offer HPV vaccines. Additionally, our results demonstrating strong evidence of quadrivalent HPV vaccine effectiveness can help the governments for making decisions about the implementation of the vaccination. It would be recommended to include the quadrivalent HPV vaccine in routine immunization programme because of its high effectiveness not only against cancer but also against GW.

In summary, our results clearly show that the ecological impact of the quadrivalent HPV vaccine is high and its introduction in many countries is strongly suggested.

\section{Supplementary information}

Supplementary information accompanies this paper at https://doi.org/10. 1186/s12889-020-08753-y.

Additional file 1 Graphical output from Copas analysis of 8 RCTs (A)

and 8 ecological studies (B) (a): Funnel plot; (b): contour plot; (c): treatment effect plot; (d): P-value plot.

\section{Abbreviations}

HPV: human papillomavirus; GW: genital wart; RCT: randomised controlled trial; FDA: Food and Drug Administration; WHO: World Health Organization; OR: odds ratio; Cl: confidence interval; PRISMA: Preferred Reporting Items for Systematic Reviews and Meta-Analyses; PICO: patient, intervention, comparison, outcome; PROSPERO: International Prospective Register of Systematic Reviews; GRADE: Grading of Recommendations, Assessment, Development and Evaluation; USA: United States of America

\section{Acknowledgements}

Not applicable.

\section{Authors' contributions}

All authors have contributed meaningfully to the paper. AM had a significant role in study searching. Study selection and data extraction were conducted independently by $A L, A S$ and $Z S M$. AL and AS assessed the risk of bias. AL prepared the raw data for analysis. NF arranged the statistical investigation. PROSPERO registration was done by JT. AL, IK, GV, BN were responsible for the interpretation of the results. $\mathrm{PH}, \mathrm{ZGY}, \mathrm{ZR}$ revised the article critically for important intellectual content, and LMCZ, SW contributed to the conception and design of the final version to be submitted. All authors read and approved the final manuscript.

\section{Funding}

The study was supported by the Economic Development and Innovation Operative Programme Grant (GINOP 2.3.2-15-2016-00048) and by the Human Resources Development Operational Programme Grant (EFOP-3.6.2-16-201700006 and EFOP-3.6.3-VEKOP-16-2017-00009) from the National Research, Development and Innovation Office. The funding agencies had no role related to the design of the study or collection, analysis, or interpretation of data or in writing the manuscript.

\section{Availability of data and materials}

Not applicable.

Ethics approval and consent to participate Not applicable.

\section{Consent for publication}

Not applicable.

\section{Competing interests}

The authors declare that they have no competing interests.

\section{Author details}

'Department of Public Health, Faculty of Medicine, University of Szeged, Dóm tér 10, Szeged 6720, Hungary. ${ }^{2}$ Institute for Translational Medicine, Medical School, University of Pécs, Pécs, Hungary. ${ }^{3}$ Department of Public Health Medicine, Medical School, University of Pécs, Pécs, Hungary. ${ }^{4}$ Department of Oral Biology, Faculty of Dentistry, Semmelweis University, Budapest, Hungary.

Received: 17 July 2019 Accepted: 22 April 2020

Published online: 28 May 2020

\section{References}

1. Committee Opinion No. 704 summary: human papillomavirus vaccination. Obstet Gynecol 2017;129(6):1155-56.

2. Pils $\mathrm{S}$, Joura EA. From the monovalent to the nine-valent HPV vaccine. Clin Microbiol Infect. 2015;21(9):827-33.

3. World Health Organization: Weekly Epidemiological Record: Human papillomavirus vaccines: WHO position paper. 2017;19(92):241-68. http:// appswhoint/iris/bitstream/handle/10665/255353/WER9219pdf;jsessionid=573 ED31BAADB8A92056F43BD30296B37? sequence=1 Accessed 20 June 2018.

4. World Health Organization: Human papillomavirus (HPV) and cervical cancer. Key facts. http://www.who.int/news-room/fact-sheets/detail/humanpapillomavirus-(hpv)-and-cervical-cancer Accessed 20 June 2018.

5. World Health Organization: Data, statistics and graphics. http://www.who. int/immunization/monitoring_surveillance/data/en/ Accessed 27 Jan 2020.

6. Drolet M, Benard E, Boily MC, Ali H, Baandrup L, Bauer H, et al. Populationlevel impact and herd effects following human papillomavirus vaccination programmes: a systematic review and meta-analysis. Lancet Infect Dis. 2015; 15(5):565-80.

7. Arbyn M, Xu L, Simoens C, Martin-Hirsch PP. Prophylactic vaccination against human papillomaviruses to prevent cervical cancer and its precursors. Cochrane Database Syst Rev. 2018;5:Cd009069.

8. Bogani G, Leone Roberti Maggiore U, Signorelli M, Martinelli F, Ditto A, Sabatucci I, et al. The role of human papillomavirus vaccines in cervical cancer: Prevention and treatment. Crit Rev Oncol Hematol. 2018;122:92-7.

9. Yakely AE, Avni-Singer L, Oliveira CR, Niccolai LM. Human papillomavirus vaccination and Anogenital warts: a systematic review of impact and effectiveness in the United States. Sex Transm Dis. 2019;46(4):213-20.

10. Drolet M, Bénard É, Pérez N, Brisson M. HPV Vaccination Impact Study Group. Population-level impact and herd effects following the introduction of human papillomavirus vaccination programmes: updated systematic review and meta-analysis. Lancet. 2019;394(10197):497-509. 
11. Steben M, Tan Thompson M, Rodier C, Mallette N, Racovitan V, DeAngelis F, Melissa Stutz M, Rampakakis E. A review of the impact and effectiveness of the Quadrivalent human papillomavirus vaccine: 10 years of clinical experience in Canada. J Obstet Gynaecol Can. 2018;40(12):1635-45.

12. Brisson M, Bénard É, Drolet M, Bogaards JA, Baussano I, Vänskä S, et al. Population-level impact, herd immunity, and elimination after human papillomavirus vaccination: a systematic review and meta-analysis of predictions from transmission-dynamic models. Lancet Public Health. 2016; 1(1):e8-e17.

13. Giuliano ARJ, Palefsky JM, Goldstone S, Moreira ED, Penny ME, Aranda C, et al. Efficacy of quadrivalent HPV vaccine against HPV infection and disease in males. N Engl J Med. 2011;364(5):401-11.

14. Westfechtel L, Werner RN, Dressler C, Gaskins M, Nast A. Adjuvant treatment of anogenital warts with systemic interferon: a systematic review and metaanalysis. Sex Transm Infect. 2018;94(1):21-9.

15. Moher D, Liberati A, Tetzlaff J, Altman DG. Preferred reporting items for systematic reviews and meta-analyses: the PRISMA statement. PLoS Med. 2009;6(7):e1000097.

16. Mikamo H, Yamagishi Y, Murata S, Yokokawa R, Han SR, Wakana A, Sawata M, Tanaka Y. Efficacy, safety, and immunogenicity of a quadrivalent HPV vaccine in Japanese men: A randomized, Phase 3, placebo-controlled study. Vaccine. 2019;37(12):1651-8.

17. Dominiak-Felden G, Gobbo C, Simondon F. Evaluating the early benefit of Quadrivalent HPV vaccine on genital warts in Belgium: a cohort study. PLoS One. 2015;10(7):e0132404.

18. Higgins JPT, Green S (editors). Cochrane Handbook for Systematic Reviews of Interventions Version 5.1.0 [updated March 2011]. The Cochrane Collaboration; 2011. http://handbook.cochrane.org.

19. DerSimonian R, Laird N. Meta-analysis in clinical trials. Control Clin Trials. 1986;7:177-88

20. Garland SM, Hernandez-Avila M, Wheeler CM, Perez G, Harper DM, Leodolter $S$, et al. Quadrivalent vaccine against human papillomavirus to prevent anogenital diseases. N Engl J Med. 2007;356(19):1928-43.

21. Dillner J, Kjaer SK, Wheeler CM, Sigurdsson K, Iversen OE, Hernandez-Avila $M$, et al. Four year efficacy of prophylactic human papillomavirus quadrivalent vaccine against low grade cervical, vulvar, and vaginal intraepithelial neoplasia and anogenital warts: randomised controlled trial. BMJ. 2010;341:C3493.

22. Majewski S, Bosch FX, Dillner J, Iversen OE, Kjaer SK, Munoz N, et al. The impact of a quadrivalent human papillomavirus (types $6,11,16,18$ ) viruslike particle vaccine in European women aged 16 to 24. J Eur Acad Dermatol Venereol. 2009;23(10):1147-55.

23. Villa LL, Costa RL, Petta CA, Andrade RP, Paavonen J, Iversen OE, et al. High sustained efficacy of a prophylactic quadrivalent human papillomavirus types 6/11/16/18 L1 virus-like particle vaccine through 5 years of follow-up. $\mathrm{Br} J$ Cancer. 2006;95(11):1459-66.

24. Munoz N, Kjaer SK, Sigurdsson K, Iversen OE, Hernandez-Avila M, Wheeler CM. Impact of human papillomavirus (HPV)-6/11/16/18 vaccine on all HPVassociated genital diseases in young women. J Natl Cancer Inst. 2010;102(5): 325-39.

25. Perez G, Lazcano-Ponce E, Hernandez-Avila M, Garcia PJ, Munoz N, Villa LL, et al. Safety, immunogenicity, and efficacy of quadrivalent human papillomavirus (types $6,11,16,18$ ) L1 virus-like-particle vaccine in Latin American women. Int J Cancer. 2008;122(6):1311-8.

26. Yoshikawa $H$, Ebihara $K$, Tanaka $Y$, Noda K. Efficacy of quadrivalent human papillomavirus (types 6, 11, 16 and 18) vaccine (GARDASIL) in Japanese women aged 18-26 years. Cancer Sci. 2013;104(4):465-72

27. Ali H, Donovan B, Wand H, Read TR, Regan DG, Grulich AE, et al. Genital warts in young Australians five years into national human papillomavirus vaccination programme: national surveillance data. BMJ. 2013;346:f2032.

28. Chow EPF, Read TRH, Wigan R, Donovan B, Chen MY, Bradshaw CS, et al. Ongoing decline in genital warts among young heterosexuals 7 years after the Australian human papillomavirus (HPV) vaccination programme. Sex Transm Infect. 2015;91(3):214-9.

29. Harrison C, Britt H, Garland S, Conway L, Stein A, Pirotta M, et al. Decreased management of genital warts in young women in Australian general practice post introduction of national HPV vaccination program: results from a nationally representative cross-sectional general practice study. PLoS One. 2014;9(9):e105967.

30. Fairley CK, Hocking JS, Gurrin LC, Chen MY, Donovan B, Bradshaw CS. Rapid decline in presentations of genital warts after the implementation of a national quadrivalent human papillomavirus vaccination programme for young women. Sex Transm Infect. 2009;85(7):499-502.

31. Read TR, Hocking JS, Chen MY, Donovan B, Bradshaw CS, Fairley CK. The near disappearance of genital warts in young women 4 years after commencing a national human papillomavirus (HPV) vaccination programme. Sex Transmit Infect. 2011;87(7):544-7.

32. Checchi M, Mesher D, Mohammed H, Soldan K. Declines in anogenital warts diagnoses since the change in 2012 to use the quadrivalent HPV vaccine in England: data to end 2017. Sex Transm Infect. 2019;95:368-73.

33. Mann LM, Llata E, Flagg EW, Hong J, Asbel L, Carlos-Henderson J, Kerani RP, Kohn R, Pathela P, Schumacher C, Torrone EA. Trends in the Prevalence of Anogenital Warts Among Patients at Sexually Transmitted Disease ClinicsSexually Transmitted Disease Surveillance Network, United States, 20102016. J Infect Dis. 2019;219(9):1389-97.

34. Garnett GP. Role of herd immunity in determining the effect of vaccines against sexually transmitted disease. J Infect Dis. 2005;191(1):S97-106.

35. Medeiros LR, Rosa DD, da Rosa MI, Bozzetti MC, Zanini RR. Efficacy of human papillomavirus vaccines: a systematic quantitative review. Int $J$ Gynecol Cancer. 2009;19(7):1166-76.

36. Patel C, Brotherton JML, Pillsbury A, Jayasinghe S, Donovan B, Macartney K, Marshall H. The impact of 10 years of human papillomavirus (HPV) vaccination in Australia: what additional disease burden will a nonavalent vaccine prevent? Euro Surveill. 2018;23(41):1700737.

37. Tejada RA, Vargas KG, Benites-Zapata V, Mezones-Holguin E, Bolanos-Diaz R, Hernandez AV. Human papillomavirus vaccine efficacy in the prevention of anogenital warts: systematic review and meta-analysis. Salud Publica Mex. 2017;59(1):84-94.

38. Kmietowicz Z. UK will use Gardasil in its HPV vaccination programme from next September. BMJ. 2011;343:d7694.

39. Oliphant J, Stewart J, Saxton P, Lo M, Perkins N, Ward D. Trends in genital warts diagnoses in New Zealand five years following the quadrivalent human papillomavirus vaccine introduction. N Z Med J. 2017;130(1452):9-16.

40. Navarro-Illana E, Lopez-Lacort M, Navarro-Illana P, Vilata JJ, Diez-Domingo J. Effectiveness of HPV vaccines against genital warts in women from Valencia. Spain Vaccine. 2017;35(25):3342-6.

41. Quattrone F, Canale A, Filippetti E, Tulipani A, Porretta A, Lopalco PL. Safety of HPV vaccines in the age of nonavalent vaccination. Minerva Pediatr. 2018;70(1):59-66.

\section{Publisher's Note}

Springer Nature remains neutral with regard to jurisdictional claims in published maps and institutional affiliations.
Ready to submit your research? Choose BMC and benefit from:

- fast, convenient online submission

- thorough peer review by experienced researchers in your field

- rapid publication on acceptance

- support for research data, including large and complex data types

- gold Open Access which fosters wider collaboration and increased citations

- maximum visibility for your research: over $100 \mathrm{M}$ website views per year

At $\mathrm{BMC}$, research is always in progress.

Learn more biomedcentral.com/submissions 